\title{
HUMAN AORTIC VALVE ALLOGRAFTS ELICIT A DONOR-SPECIFIC IMMUNE RESPONSE
}

\author{
Patrick Hogan, FRACP, FRCPA ${ }^{a}$ \\ Lynette Duplock, MSc ${ }^{\mathrm{a}}$ \\ Marjorie Green, $\mathrm{PhD}^{\mathrm{b}}$ \\ Susan Smith, BSc ${ }^{c}$ \\ Kenneth L. Gall, BAppSc ${ }^{c}$ \\ Ian H. Frazer, FRCP, FRCPA ${ }^{a}$ \\ Mark F. O'Brien, FRCS, FRACS
}

\begin{abstract}
Objective: The nature and magnitude of the immunologic response to implantation of human cryopreserved aortic valve allografts was investigated. Methods: Twenty aortic valve allograft recipients were investigated for donor-specific antibody and T-cell-mediated responses with serial flow cytometric and microlymphocytotoxic crossmatch assays and one-way mixed lymphocyte cultures. Results: Donor-specific immunoglobulin G antibodies to class I and II human leukocyte antigens were first detected in the serum of all aortic valve allograft recipients at 30 days after implantation and persisted in substantial amounts in all but one of the recipients at day 365. Recipient $T$-cell alloreactivity toward donor lymphocytes was significantly increased at day $\mathbf{3 0}$ compared with levels before and 10 days after operation. Conclusions: Cryopreserved aortic valve allografts elicit a substantial allogeneic response in recipients. This alloreactivity may contribute to the observed morphologic changes in aortic valve allografts and eventual long-term deterioration of allograft function. (J Thorac Cardiovase Surg 1996;112:1260-7)
\end{abstract}

A ortic valve allografts (AVAs) sterilized by lowdose antibiotics followed by early cryopreservation (i.e., viable cryopreserved AVAs) combine the best long-term performance with the lowest complication rate compared with alternative aortic valve replacements. ${ }^{1,2}$ Comparison of human AVAs prepared by various methods indicates that the durability of cryopreserved AVAs may be explained by adequate tissue matrix preservation and possibly by survival of fibroblasts, which maintain the integrity of the AVAs for some time. ${ }^{2,3}$ Hemodynamic failure of an AVA as a result of degeneration of the valve matrix may be caused by immunologic destruction of fibroblasts or by prolonged mechanical stress

From the Lions Human Immunology Laboratories, ${ }^{a}$ and the University of Queensland Department of Surgery, ${ }^{b}$ Princess Alexandra Hospital, and the Department of Cardiac Surgery, The Prince Charles Hospital, ${ }^{\mathrm{C}}$ Brisbane, Australia.

Supported by The Prince Charles Hospital Foundation.

Read at the Seventy-sixth Annual Meeting of The American Association for Thoracic Surgery, San Diego, Calif., April 28-May 1, 1996.

Received for publication May 6, 1996; revisions requested June 11, 1996; revisions received July 1, 1996; accepted for publication July 1, 1996.

Address for reprints: M. O'Brien, MD, Department of Cardiac Surgery, The Prince Charles Hospital, Rode Road, Chermside 4032. Brisbane, Australia.

Copyright @ 1996 by Mosby-Year Book, Inc.

$0022-5223 / 96 \$ 5.00+0 \quad \mathbf{1 2 / 6 / 7 6 2 5 1}$ after leaflet distortion at implantation. ${ }^{4,5}$ Attempts to understand and possibly modify the process of degeneration are particularly relevant to treating younger recipients, in whom degeneration is known to occur earlier. 4

The significance of an antiallograft immune response cannot be determined until the frequency, evolution, and magnitude of the main components of the reaction are defined. Previous studies from our group with the use of a heterotopic AVA rat model documented the evolution of both a donorspecific antibody and a T-cell-mediated immune response to fresh AVA tissue. ${ }^{6}$ The strategies of that study were repeated in the current study, which reports the findings of prospective assays of antibody and $\mathrm{T}$-cell responses to donor antigens in a group of 20 patients receiving cryopreserved AVAs during cardiac operations.

\section{Patients and methods}

Recipients and donors. Twenty recipients of AVAs comprising 17 men and 3 women (median age 47 years; range 20 to 69 years) were studied. Individual AVA recipients were designated by numbers 1 through 20 , indicating their order of entry into the study. Replacements with AVA were carried out for degenerative aortic valve disease in 17 patients (including one replacement for a previous AVA). Pulmonary valve allografts were used to replace pulmonary valves in two patients with congenital right heart disease and in one patient whose own pulmonary valve was used as an autograft replacement of the 
diseased aortic valve. An all-male control group (median age 64 years; range 49 to 71 years), included to ascertain the effect of operation and anesthesia, comprised five recipients of mechanical aortic valves (MV) and one recipient of a xenograft aortic valve (XV) $(0.2 \%$ glutaraldehyde-fixed porcine graft, Medtronic Intact, Minneapolis, Minn.) implanted for degenerative aortic valve disease.

Fifteen patients had complete aortic root replacements, two had subcoronary aortic valve replacements (one with pulmonary autograft), one had an aortic valve replacement with the intraluminal cylinder technique, and two had pulmonary valve replacements alone. Concomitant surgical procedures included coronary artery bypass in two recipients and two control patients and a mitral valve replacement in one control patient.

Two recipients of AVA were taking antiinflammatory doses $(<0.5 \mathrm{mg} / \mathrm{kg} /$ day $)$ of prednisone for treatment of chronic asthma. Transfusions of Red blood cells were given perioperatively to four AVA recipients (to a maximum of 4 units), one MV and one XV recipient (1 and 12 units). Except for the patient who received an AVA 6 years previously, no recipient had prior exposure to allogeneic human tissue.

Serum or heparin-treated venous blood were obtained from recipients of AVAs immediately before operation (day 0 ) and approximately on days 10, 30, 90, and 365 after implantation. Control sera were taken at identical times from the MV and XV recipients.

Research protocols were approved by The Prince Charles and Princes Alexandra Hospitals' Medical Ethics Advisory Committees. All valve recipients studied gave informed consent before participation.

Allograft preparation. AVAs were obtained from multiorgan donors and the native hearts of heart transplant recipients. The valves were processed as soon as possible after crossclamp application and stored by the Queensland Heart Valve Bank at The Prince Charles Hospital with the use of techniques developed by O'Brien and colleagues. ${ }^{7}$ Valves obtained from multiorgan donors were incubated for 6 hours at $37^{\circ} \mathrm{C}$ in Nutrient Medium 199 (M199, CSL, Parkville, Australia) containing the antibiotics penicillin (CSL, $30 \mu \mathrm{g} / \mathrm{ml}$ ) and streptomycin $(\mathrm{CSL}, 50 \mu \mathrm{g} / \mathrm{ml})(\mathrm{M} 199+\mathrm{AB})$. Valves obtained from heart transplant recipients received a brief wash in $\mathrm{M} 199+\mathrm{AB}$ only. The valves were then placed in $100 \mathrm{ml}$ of M199 containing $10 \%$ dimethylsulfoxide (DMSO) (Merck, Darmstadt, Germany) and heat sealed inside two Fenwal Cryocyte Freezing containers (Baxter Healthcare Co., Deerfield, Ill.).

The packaged valves were then cryopreserved in a controlled-rate freezer (Model 1010A, Cryomed, Mt. Clemens, Mich.) at a rate of $-1^{\circ} \mathrm{C} /$ minute down to $-40^{\circ} \mathrm{C}$ and then transferred to the vapor phase of a liquid nitrogen freezer (Model 17K, Taylor-Wharton, Indianapolis, Ind.) at temperatures below $-135^{\circ} \mathrm{C}$. The valves were stored for a minimum of 3 weeks before use. Only valves that demonstrated no microbial contamination in tissue and fluid samples at the time of cryopreservation were released. When required for implantation, the selected valve was removed from the outer package and thawed in a $37^{\circ} \mathrm{C}$ saline bath, followed by four sequential 2-minute washouts of the DMSO (i.e., 5\% DMSO in M199, 2.5\% DMSO in M199, M199 only, and M199 only).

Donor mononuclear cells (MC) were isolated from multiorgan donor spleen or lymph nodes and from heparin-treated venous blood of heart transplant recipients immediately before transplantation.

Isolation of mononuclear cells. Peripheral blood mononuclear cells (PBMC) were isolated from heparintreated venous blood by means of density gradient centrifugation with Ficoll-Paque (Pharmacia LKB Biotechnology AB, Uppsala, Sweden). Heparin-treated blood diluted 1:2 with Hanks balanced salt solution (HBSS) with $0.35 \mathrm{gm} / \mathrm{L}$ sodium bicarbonate without phenol red or RPMI 1640 medium (Gibco, Grand Island, N.Y.) with 2 $\mathrm{mmol} / \mathrm{L}$ glutamine, $100 \mu \mathrm{g} / \mathrm{ml}$ penicillin, and $100 \mu \mathrm{g} / \mathrm{ml}$ streptomycin was layered on Ficoll-Paque and centrifuged at $800 \mathrm{~g}$ for 25 minutes. The PBMC were collected and washed twice in RPMI 1640.

MC were isolated from lymph nodes or spleen by repeatedly flushing and aspirating a subcapsular portion of the tissues with 40 to $50 \mathrm{ml}$ of RPMI 1640 through a 23-gauge needle. The MC were dispersed by a further five aspirations through the needle and were then centrifuged over Ficoll-Paque at $800 \mathrm{~g}$ for 25 minutes and washed twice in RPMI 1640. MC and PBMC were then resuspended in RPMI 1640 with $20 \%$ human A serum and $20 \%$ DMSO (Sigma Chemical Co., St. Louis, Mo.) and cryopreserved in liquid nitrogen at $-196^{\circ} \mathrm{C}$. All MC populations were found to be greater than $95 \%$ viable by means of trypan blue exclusion after thawing for use in assays.

Flow cytometric crossmatch. Serial serum specimens from recipients were tested for donor-specific antibodies against $\mathrm{T}$ and $\mathrm{B}$ cells from the AVA donor and human leukocyte antigens (HLA) A-, B-, C-, and DR-disparate third party control subjects by flow cytometric crossmatch (FCCM) as previously described. ${ }^{6} \mathrm{MC}$ were washed twice in HBSS containing $10 \%$ fetal bovine serum (FBS) and then preincubated in HBSS with $10 \%$ FBS at $37^{\circ} \mathrm{C}$ for 20 minutes to reduce nonspecific antibody binding. Donor and control MC ( 2 to $5 \times 10^{5}$ in $\left.25 \mu \mathrm{l}\right)$ were incubated with $20 \mu$ l aliquots of recipient, pooled negative control, or pooled positive control serum at room temperature and then washed twice in HBSS containing $2 \%$ FBS. Negative sera were from normal subjects with no history of pregnancy, blood transfusion, or organ transplantation. Positive sera were from sensitized recipients of failed renal allografts with high-titer anti-HLA antibodies.

The cells were incubated in the dark for 20 minutes at room temperature with $30 \mu \mathrm{L}$ of an antibody mixture containing $0.5 \mu \mathrm{l}$ fluorescein isothiocyanate-conjugated $\mathrm{F}\left(\mathrm{ab}^{\prime}\right)_{2}$ rabbit anti-human IgG or IgM (DAKO, Glostrup, Denmark), $5 \mu \mathrm{l}$ Phycoerythrin (PE)-conjugated antiCD20 (DAKO), and $2 \mu$ PE-conjugated anti-Leu 4 (CD3) diluted with $10 \mu$ l of unconjugated anti-Leu 4-purified antibody (Becton Dickinson, San Jose, Calif.) and HBSS with $2 \%$ FBS. The MC were then washed in HBSS with $2 \%$ FBS and fixed by the addition $150 \mu \mathrm{l}$ of fixative ( $1 \%$ formalin, $2.5 \%$ glucose, and $0.2 \%$ sodium azide).

Antibodies to $\mathrm{T}$ or B cells were detected by using dual color immunofluorescence in a flow cytometer (Coulter Elite, Hileah, Fla.). The level of bound antibody was expressed as the channel number of mean peak fluores- 
Table I. Serial levels of recipient antibodies

\begin{tabular}{lllccc}
\hline Targets $^{*}$ & Day $0 \%$ & Day 10 & Day 30 & Day 90 & Day 365 \\
\hline Donor T & $17 \pm 6$ & $17 \pm 7$ & $208 \pm 173$ & $543 \pm 218$ & $511 \pm 267$ \\
Donor B & $56 \pm 36$ & $55 \pm 37$ & $466 \pm 272$ & $937 \pm 339$ & $758 \pm 306$ \\
Contr. T & $15 \pm 6$ & $15 \pm 5$ & $59 \pm 30$ & $208 \pm 58$ & $243 \pm 190$ \\
Contr. B & $42 \pm 24$ & $38 \pm 20$ & $203 \pm 147$ & $456 \pm 254$ & $431 \pm 228$ \\
MV/XV T & $24 \pm 1$ & $24 \pm 2$ & $25 \pm 1$ & $24 \pm 3$ & nd \\
MV/XV B & $50 \pm 10$ & $50 \pm 7$ & $52 \pm 6$ & $51 \pm 15$ & nd
\end{tabular}

$n d=$ Not done.

*Serial aortic valve allograft (AVA) recipient sera were tested by flow cytometric crossmatch against T and B cells from AVA donors and HLA-disparate third-party controls. Mechanical or xenograft aortic valves (MV/XV) were tested against control cells. Day 0 sera were collected immediately before AVA surgery.

†Values shown represent the mean \pm 1 standard deviation of peak channel fluorescence for each of the days.

cence intensity on a 3-decade log scale. To ensure consistency between assays, aliquots of the pooled negative and positive control serum were used in each assay, and results were accepted only if the control results fell within 1 standard deviation of the mean of repeated estimations. Reactivity toward $\mathrm{T}$ cells indicated the presence of antiHLA class I antibodies, and B-cell reactivity indicated the presence of class I and/or class II antibodies. ${ }^{6,8}$

Recipient antibody HLA specificity. Detection and specificity of recipient anti-HLA antibodies was determined by typing against representative $T$ - and $B$-cell panels using the National Institutes of Health (NIH) microlymphocytotoxicity assay. ${ }^{9}$ Undiluted sera in $1 \mu \mathrm{l}$ aliquots were added to Terasaki microwells prefilled with light mineral oil containing $2 \mu \mathrm{l}$ of T-cell or B-cell suspensions (at $2 \times 10^{6} / \mathrm{L}$ ) previously isolated from peripheral blood or spleen by immunomagnetic bead separation. After incubation for 30 minutes at room temperature, $5 \mu \mathrm{l}$ of noncytotoxic rabbit complement was added for 90 minutes, and then $5 \mu \mathrm{l}$ of $4 \%$ aqueous eosin was admixed, followed in 2 minutes by $5 \mu \mathrm{l}$ of formalin to detect nonviable cells. Cytotoxicity was assessed manually in each microwell on a Lambda Scan Plus (One Lambda Inc., Los Angeles, Calif.) and graded on an increasing scale from 1 ( $<5 \%$ lysis) to 8 ( $>95 \%$ lysis). Antibody specificities were assigned by an experienced tissue-typing scientist in a blinded fashion according to the patterns of significant cytotoxicity.

Mixed lymphocyte culture. All cryopreserved stimulator (donor) and responder (recipient) cells were thawed simultaneously for the mixed lymphocyte culture (MLC) assay. Recipient PBMC were used as responders to test for the presence of donor-specific proliferative T-cell responses against irradiated (2500 cGy) stimulator $\mathrm{MC}$ from donor and third-party control peripheral blood, spleen, or lymph nodes. Stimulator MC $\left(1 \times 10^{5}\right)$ and responder PBMC $\left(1 \times 10^{5}\right)$ taken at each time before and after implantation were incubated for 2 days at $37^{\circ} \mathrm{C}$ in an atmosphere of $5 \% \mathrm{CO}_{2}$ in air in quadruplicate in $200 \mu \mathrm{l}$ of RPMI 1640 containing $20 \%$ human pooled sera, $2 \mathrm{mmol}$ glutamine, $100 \mu \mathrm{g} / \mathrm{ml}$ penicillin, and $100 \mu \mathrm{g} / \mathrm{ml}$ streptomycin in round-bottom microwells.

Proliferation was measured on a beta scintillation counter (LKB Wallac 1205 Betaplate, Turku, Finland) after incubating the cells in each well with $1 \mu \mathrm{Ci}$ of tritiated thymidine for 18 hours before harvesting. Triti- ated thymidine incorporation was expressed as the stimulation index (SI), calculated by the formula: $\mathrm{SI}=$ Mean counts per minute (experimental)/Mean counts per minute (autologous). Autologous counts were obtained by coculturing nonirradiated and irradiated responder $\mathrm{MC}$ at each time.

Cell viability, as determined by means of trypan blue exclusion, was always greater than $95 \%$, and proliferative ability of responders was confirmed in each assay by incubation with phytohemagglutinin $(10 \mu \mathrm{g} / \mathrm{well})$.

Statistics. Comparisons between paired groups were made with the Wilcoxon matched-pair signed-rank test and between unrelated pairs using the Wilcoxon rank sum test (Stata Statistical Package 3.0; Stata Corporation, College Station, Tex.).

\section{Results}

Recipient antibody response. Ten AVA recipients (numbers 1 through 10) studied serially by FCCM demonstrated antidonor IgG antibodies in every case (Table I and Fig. 1). Low levels of reactivity comparable to those of MV or XV recipients and pooled negative control sera (results not shown) were observed against donor $\mathrm{T}$ and $\mathrm{B}$ cells in all patients at days 0 and 10 after AVA implantation.

Significantly increased reactivity was detected in recipients at 30 days $(p<0.005$ for T cells and $p<$ 0.005 for B cells), 90 days ( $p<0.005$ and $p<0.005$ ), and 365 days $(p<0.008$ and $p<0.008)$ compared with day 0 antibody levels. There was no explanation for the markedly lower anti-T-cell and anti-B-cell antibody response observed in only one of the recipients (recipient 2), which by day 365 had fallen to within 3 standard deviations of the day 0 mean antibody levels. Significant IgM responses were not observed at any of the times for the first three patients tested (data not shown). The antibody levels of the four recipients who received only aortic valves did not differ significantly from those of the remaining six who received the larger combined valve and root replacements (data not shown). 

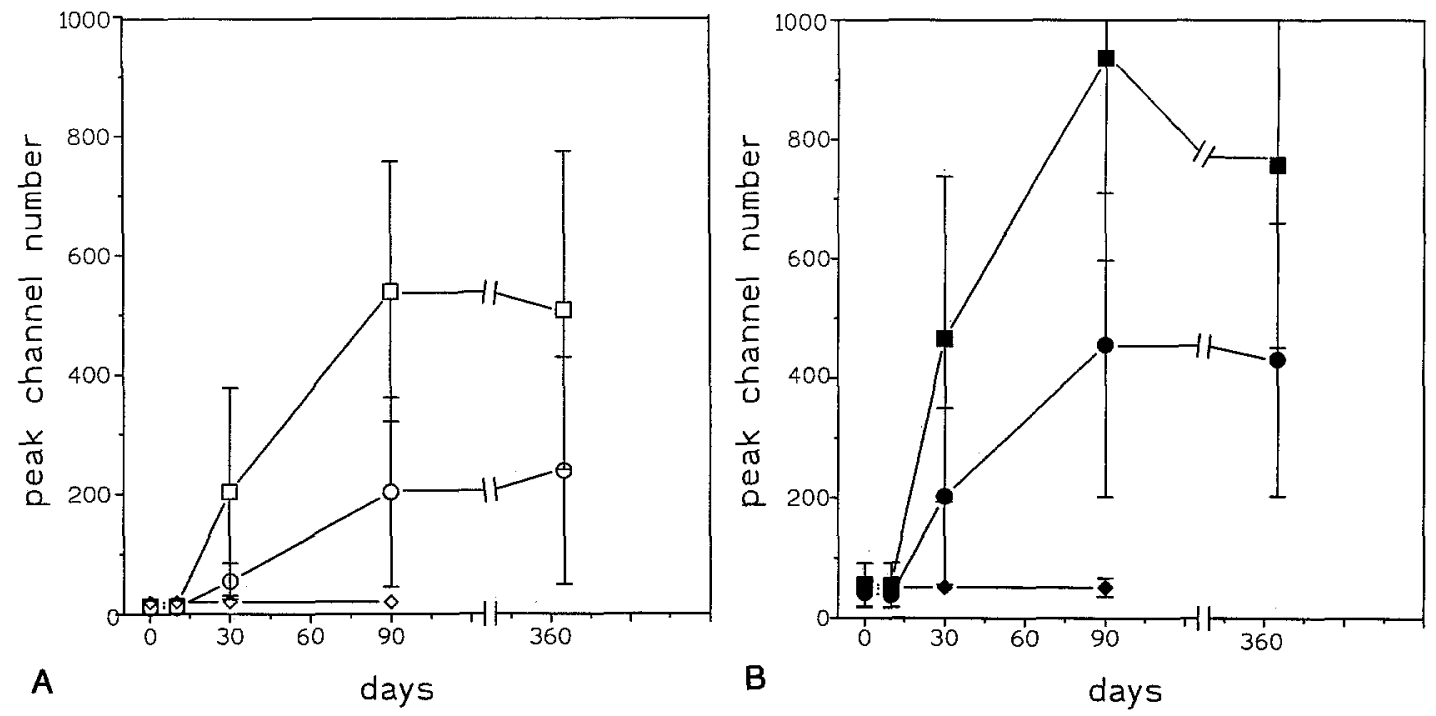

Fig. 1. Anti-donor IgG antibodies measured serially by flow cytometric crossmatch. Mean antibody levels (with 1 standard deviation bars) are expressed as the channel number corresponding to peak cell fluorescence on a 3-decade $\log$ scale. The antibody levels against $T$ (A) and B (B) cells are indicated for recipient sera tested against donor $(\square, \boldsymbol{\square})$ and third-party $(O, \bullet)$ cells and for recipients of MV or XV tested against third-party cells $(\diamond, \diamond)$.

Recipient sera were also tested against $\mathrm{T}$ and $\mathrm{B}$ cells from normal control cells (selected to have no HLA A, B, and DR antigens in common with the AVA donor). All 10 recipients studied showed significant reactivity to nondonor HLA antigens, but these responses were significantly lower than antidonor responses at 30 days $(p<0.016$ and $p<$ $0.028), 90$ days $(p<0.003$ and $p<0.003)$, and 365 days $(p<0.038$ and $p<0.012)$. Control recipients of MV or XV (including two recipients of blood transfusions) showed no significant increase in antibody reactivity against control $\mathrm{T}$ and $\mathrm{B}$ cells (see Table 1 and Fig. 1).

Recipient antibody HLA specificity. The HLA specificities of antibodies from 13 AVA recipients (recipients 1 through 13) at 90 days were identified by NIH microcytotoxicity (Table II). Donor HLA class I- or class II-specific antibodies were demonstrated in 7 of 13 and 4 of 11 recipients, respectively. The anti-B27 antibody in patient 3 is a well-recognized cross reactivity with $B 7$, and in patient 10 , anti-B55 was strongly cross-reactive with B56, which was present in the donor. ${ }^{10,11}$ Multispecific reactivity against more than $50 \%$ of panel $\mathrm{T}$ and $\mathrm{B}$ cells was detected in all recipients.

Broad reactivity against the screening cell panels is common in recipients after solid organ transplantation and may be mediated by antibodies directed
Table II. HLA specificities of recipient antibodies

\begin{tabular}{rcc}
\hline & Class I & Class II \\
\hline 1 & A2, B35, B51* & - \\
2 & A32 & - \\
3 & A24, B55, B7, B27 & DQ1 \\
4 & - & - \\
5 & - & - \\
6 & - & DR11 \\
7 & - & DR7 \\
8 & $\mathbf{B 7}$ & - \\
9 & - & - \\
10 & A24, B55, B57 & nd \\
11 & A2 & nd \\
12 & A2 & - \\
13 & - & \\
\hline
\end{tabular}

-, no specific antibodies detected; $n d$, Not done.

*The data in bold type indicate antigens in the aortic valve allograft donor. Numbers represent individual recipients.

against monomorphic HLA determinants or nonHLA surface antigens. All four recipients lacking donor-specific antibodies had greater than $90 \%$ multispecific panel reactivity, which might have obscured specific HLA reactivities. In AVA recipients antibodies specific for donor HLA that target class I developed more frequently than class II antigens.

Recipient T-cell responses. Peripheral blood $\mathrm{T}$ cells taken from seven recipients (recipients 10 and 15 through 20) before and after AVA implantation 
Table III. Recipient mixed lymphocyte culture reactivity against donor and control peripheral blood mixed lymphocytes

\begin{tabular}{|c|c|c|c|c|}
\hline Patients & Day 0 & Day 10 & Day 30 & Day 90 \\
\hline $10-D^{*}$ & 4.4 & 2.2 & 9.0 & 7.5 \\
\hline $10-\mathrm{C}$ & 2.3 & 1.6 & 2.7 & 2.6 \\
\hline $15-\mathrm{D}$ & 1.9 & 1.7 & 7.3 & 3.9 \\
\hline $15-\mathrm{C}$ & 2.9 & 1.6 & 2.8 & 3.9 \\
\hline $16-\mathrm{D}$ & 2.2 & 4.1 & 66.7 & 13.7 \\
\hline $16-\mathrm{C}$ & 3.5 & 6.6 & 13.1 & 10.9 \\
\hline $17-D$ & 4.7 & 6.3 & 33.8 & 30.9 \\
\hline $17-\mathrm{C}$ & 5.4 & 7.5 & 12.3 & 14.2 \\
\hline $18-\mathrm{D}$ & 7.6 & - & 22.6 & 13.6 \\
\hline $18-\mathrm{C}$ & 5.5 & - & 13.0 & 6.9 \\
\hline 19-D & 8.0 & 6.8 & 8.6 & 15.0 \\
\hline $19-\mathrm{C}$ & 3.7 & 4.0 & 4.5 & 6.2 \\
\hline 20-D & 3.0 & 3.5 & 8.6 & 15.0 \\
\hline $20-\mathrm{C}$ & 6.3 & 6.6 & 8.2 & 8.4 \\
\hline Donor & $4.5 \pm 2.5$ & $4.1 \pm 2.1$ & $22.4 \pm 22.0$ & $12.7 \pm 9.2$ \\
\hline Control & $3.9 \pm 1.3$ & $4.7 \pm 2.6$ & $8.1 \pm 4.8$ & $7.6 \pm 4.0$ \\
\hline
\end{tabular}

Values shown for each subject (indicated by number) are the stimulation indices from the mixed lymphocyte culture against donor (D) and control (C). Values in the last two rows represent mean \pm 1 standard deviation of stimulation indices. Control stimulator cells were from HLA-disparate third parties.

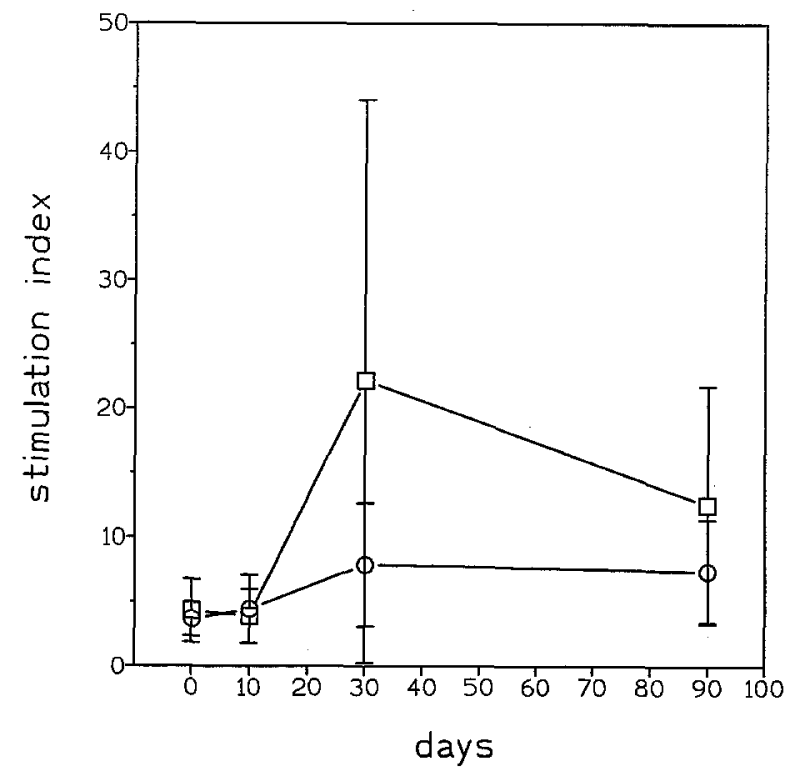

Fig. 2. Recipient T-cell reactivity measured serially in a one-way mixed lymphocyte culture. Reactivities (expressed as mean stimulation indices with 1 standard deviation bars) against donor $(\square)$ and third-party cells $(O)$ are shown.

were investigated for proliferative responses against stimulator donor PBMC in a one-way 2-day MLC (Fig. 2 and Table III). The objective of these experiments was to detect an accelerated $\mathrm{T}$-cell response to donor PBMC in recipients by comparing the MLC reactivities of each individual at certain times after surgery with baseline levels before implantation. Significantly increased recipient reactivity toward donor PBMC was observed in samples taken at 30 days in recipients $(p<0.018)$ compared with the day 0 preimplantation mean SI; mean levels at 10 days and 90 days were not significantly different ( $p<0.917$ and $p<0.18$, respectively).

The specificity of the anti-donor $\mathrm{T}$-cell response was investigated by the inclusion of HLA-disparate control stimulator PBMC in the MLC at each time point for the seven recipients. There was no significant difference between donor and thirdparty reactivity at any of the times, although there was an evident trend at 30 days $(p<0.142$ at 30 days). The MLC reactivity to donor or third-party cells was not atypical in two of the recipients who received blood transfusions, both of whom had levels of reactivity toward the lower end of the range. Patient 18 (who had received an AVA 6 years previously) had the third highest levels of donor-specific MLC reactivity. These data indicate that 30 days after AVA implantation recipients have significantly increased numbers of circulating alloreactive $\mathrm{T}$ cells compared with their preimplantation baseline.

\section{Discussion}

Previously there were limited data available on the immunogenicity of the human cryopreserved AVA, but this study shows that all recipients are 
likely to form IgG- and T-cell-mediated reactions to donor HLA antigens. Developing in parallel with this specific reactivity were broadly reactive antibodies, which occur in recipients of vascularized solid organ allografts. ${ }^{9-11}$ The wide range of $\mathrm{T}$-cell reactivities may reflect the degree of HLA mismatch between recipient and donor. Long-term clinical studies would be required to determine whether the degree of T-cell stimulation could be one determinant of accelerated AVA degeneration.

$\mathrm{T}$ cells of the $\mathrm{CD} 4^{+}$"helper" phenotype initiate MLC reactivity by recognition of nonself HLA class II molecules and associated costimulatory B7 molecules on donor antigen-presenting cells. The T-cell and antibody responses observed in AVA recipients probably are supported by the cytokine-secreting functions of this T-cell subset. ${ }^{12,13}$

Donor-specific $\mathrm{T}$ cells are likely to be the main agents of AVA injury, effected through secretion of high levels of cytokines such as interleukin-2 and interferon- $\gamma$, which have proinflammatory and cytodestructive potential. ${ }^{13-15}$ Anti-donor antibodies accompanying AVA implantation are likely to be a relatively innocuous consequence of T-cell activation. Anti-HLA antibodies frequently arise after solid organ allograft implantation without adverse impact on graft function, in contrast to the preexisting antibodies that predispose to hyperacute rejection. $^{16}$

Past experimental and clinical studies have proved that aortic valve tissue is immunogenic. Anti-donor antibody responses followed implantation of fresh AVA in a rat model ${ }^{6}$ and in human recipients of noncryopreserved AVA in whom antiHLA antibodies were detected as early as 1 week. In this clinical study, only donor HLA class I-specific antibodies were identified, perhaps because of reduced or altered viability of the AVA. ${ }^{17}$ Recipient proliferative or cytotoxic $\mathrm{T}$-cell responses to fresh or cryopreserved AVA were detected in vivo in animal models. ${ }^{6,18-20}$ In vitro fresh or cryopreserved human aortic valve fragments or valve-derived endothelial cells stimulated allogeneic T cells. ${ }^{21}$

The location of induction and amplification of the immune response to the AVA remains unknown. Dendritic cells, which have been identified in human great vessels, ${ }^{22}$ together with endothelial cells, are capable of presenting foreign HLA class I and II antigens to recipient $\mathrm{T}$ cells. ${ }^{21,23,24}$ After an immunologic reaction involves the AVA, the density of HLA antigens on these cells and surviving fibroblasts and myocytes would be amplified by locally secreted interferon- $\gamma$ and tumor necrosis factor$\alpha .{ }^{14,15}$ Approximately $50 \%$ of AVA fibroblasts survive cryopreservation, ${ }^{3,7}$ but the extent to which endothelial and dendritic cells retain function is unknown. If alloantigen-presenting cells survive in the AVA, initial activation of T cells may occur in the graft, but presentation of donor HLA antigens liberated from the AVA may also occur in regional lymph nodes. Periodic reactivation of primed T cells by recirculation through the graft or nodes would maintain the allogeneic response until all HLA antigen in the valve was degraded.

What are the consequences of a humoral and cellular allogeneic response arising against a cryopreserved AVA? There are few clinical data from which to gauge the pathogenic potential of the human AVA response. Although the limited numbers of explanted AVA do not reveal convincing signs of an immunologic reaction, the occurrence of leaflet thickening, fibrosis, and calcification in the young recipient strongly suggests immunologic valve damage. ${ }^{4,5}$

Implantation of a cryopreserved AVA stimulates a substantial immune response to donor antigens that may destroy viable matrix fibroblasts. In the absence of repair and remodeling functions provided by fibroblasts, accelerated deterioration of the matrix may lead to degenerative failure. A limited course of immune suppression designed to minimize the immune response to AVA antigens may enhance the long-term survival of matrix fibroblasts. However, the risks of immune suppression would have to be very low because of the current clinical performance of the AVA ( $70 \%$ freedom from structural deterioration at 20 years). ${ }^{25}$ Further studies will explore the potential benefit of immune suppression in animal AVA models and will identify the cytokines involved in the human response to the AVA.

We thank Mr. S. C. Lee for his assistance with the flow cytometric crossmatch; Mr. B. Robson and Ms. L. Clifford for their assistance with the microlymphocytotoxic assays; Ms. C. Wilmette for her support in collection of materials and Drs. E. G. Stafford, M. A. H. Gardner, P. G. Pohlner, Tesar P. Mau, and R. Tam for their permission to include their patients in this study.

\section{REFERENCES}

1. Gall K, Smith S, Willmette C, Wong M, O'Brien MF. Allograft heart valve sterilization: a six-year in-depth analysis of a twenty-five-year experience with low-dose antibiotics. J Thorac Cardiovase Surg 1995;110:680-7.

2. O'Brien MF, McGiffin DC. Aortic and pulmonary allografts in contemporary cardiac surgery. Adv Card Surg 1990;1:1-24. 
3. O'Brien MF, Johnston N, Stafford G, et al. A study of the cells in the explanted viable cryopreserved allograft valve. J Card Surg 1988;3:279-87.

4. Clarke DR, Campbell DN, Hayward AR, Bishop DA. Degeneration of aortic valve allografts in young recipients. $J$ Thorac Cardiovase Surg 1993;105:934-42.

5. Mitchell RN, Jonas RA, Schoen FJ. Structure-function correlations in cryopreserved allograft cardiac valves. Ann Thorac Surg 1995;60:S108-13.

6. Zhao XM, Green M, Frazer IH, Hogan PG, O'Brien MF. Donor-specific immune response after aortic valve allografting in the rat. Ann Thorac Surg 1994;57:1158-63.

7. O'Brien MF. Homografts and autografts. In: Baue AE, Geha AS, Hammond GI, Laks H, Naunheim KS, editors. Glenn's thoracic and cardiovascular surgery. 6th ed. Stamford, CT: Appleton \& Lange. 1996.

8. Chapman JR, Deierhoi MH, Carter NP, Ting A, Morris PJ. Analysis of flow cytometry and cytotoxicity crossmatches in renal transplantation. Transplant Proc 1985;17:2480-3.

9. Hopkins KA. Basic microlymphocytotoxicity test. In: Zachary AA, Teresi GA, editors. ASHI laboratory manual. 2nd ed. American Society for Histocompatibility and Immunogenetics, New York: 1990:195-201.

10. Sullivan K, Leech SH. Concepts and background of histocompatibility testing. In: Tardif GN, MacQueen JM, eds. Tissue typing reference manual. $3 \mathrm{rd}$ ed. South-Eastern Organ Procurement Foundation, Richmond: 1993:A1;22-3.

11. Helman SW. Patient serum screening. In: Tardif GN, MacQueen JM, editors. Tissue typing reference manual. 3rd ed. South-Eastern Organ Procurement Foundation, Richmond: 1993:B21:1-9.

12. Symington FW, Brady W, Linsley PS. Expression and function of B7 on human epidermal Langerhans cells. J Immunol 1993;150:1286-95.

13. Sherman LA, Chattopadhyay S. The molecular basis of allorecognition. Ann Rev Immunol 1993;11:385-402.

14. Ansari AA, Sundstrom JB, Runnels H, et al. The absence of constitutive and induced expression of critical cell-adhesion molecules on human cardiac myocytes. Transplantation 1994; 57:942-9.

15. Pober JS, Collins T, Gimbrone MA, Libby P, Reiss CS. Inducible expression of class II major histocompatibility complex antigens of vascular endothelium. Transplantation 1986;41:141-6.

16. Patel R, Terasaki PI. Significance of the positive crossmatch test in kidney transplantation. N Engl J Med 1969;280:735-9.

17. Smith JD, Ogino H, Hunt D, Laylor RM, Rose ML, Yacoub MH. Humoral immune response to human aortic valve allografts. Ann Thorac Surg 1995;60:S127-30.

18. Khatib HE, Lupinetti FM. Antigenicity of fresh and cryopreserved rat valve allografts. Transplantation 1990;49:765-7.

19. Yankah AC, Wottge HU, Muller-Ruchholtz W. Prognostic importance of viability and a study of a second set allograft valve: an experimental study. J Card Surg 1988;3:263-70.

20. Cochran RP, Kunzelman BS. Cryopreservation does not alter antigenic expression of aortic allografts. J Surg Res 1989;46: 597-9.

21. Hoekstra F, Knoop C, Aghai Z, et al. Stimulation of immunecompetent cells in vitro by human cardiac valve-derived endothelial cells. Ann Thorac Surg 1995;60:\$131-4.

22. Bobryshev $\mathrm{YV}$, Lord RS. S-100 positive cells in human arterial intima and in atherosclerotic lesions. Cardiovasc Res 1995;29:689-96.

23. Pober IS, Collins T, Gimbrone MA, Libby P, Reiss CS. Inducible expression of class II major histocompatibility complex antigens of vascular endothelium. Transplantation 1986;41:141-6.

24. Hughes CC, Savage CO, Pober JS. The endothelial cell as a regulator of T-cell function. Immunol Rev 1990;117:85-102.

25. O'Brien MF, Stafford EG, Gardner MAH, et al. Allograft aortic valve replacement: long term follow up. Ann Thorac Surg 1995;60:S65-70.

\section{Discussion}

Dr. Mark F. Lupinetti (Seattle, Wash.). I congratulate Dr. Hogan and his associates for their outstanding contribution to our understanding of the consequences of allograft valve implantation. These data unequivocally demonstrate that the recipient of an allograft valve is sensitized to the donor antigens and that this sensitization persists for a long, long time. This is an elegant extension of your laboratory's experimental studies. It is of great reassurance to those of us who have relied heavily on the rat allograft valve model because it suggests that extrapolations made from that model do have validity to humans.

I think these findings are very important clinically because they demonstrate the limited ability of cryopreservation processing in altering immunogenicity. I think these findings are also important clinically because the durability of the sensitization suggests that a short course of immunosuppression, as someone suggested, is unlikely to be efficacious.

I would like to ask for your comments, Dr. Hogan, regarding two areas of further inquiry that are suggested by your research. First, what, if any, evidence is there that the sensitization reproducibly contributes to degeneration of the valve? I infer from your manuscript that the patients in this study are continuing to do well and the valves are continuing to function. It seems, then, that we are left with a tissue that is uniformly immunogenic but one that your institution has shown can be expected to last for 15 years, 20 years, and maybe longer. How do we make sense of this?

Second, are our current methods of immunologic assay sufficiently precise to allow us to grade sensitization? Can we identify patients as being strongly sensitized or weakly sensitized to predict which patients may be at greater or lesser risk for valve-related complications? If that is true, should we be performing routine immune surveillance on all recipients of allograft valves?

Dr. Hogan. Thank you for your comments. Your first question is the crux of the matter, which given the constraints on the human system, is unanswerable. At a previous session I asked whether there might be very sensitive echocardiographic methods that could detect thickening and nodularity of the valve. Detailed imaging studies may give some idea of what is happening early on in the implanted valve. I doubt whether there is ever going to be an answer to this question, and if we do eventually come to immune suppression, the clinical end points are years out. I really cannot answer the first question better than that. I guess that is why we are looking at cytokines. Maybe we will see some critical 
early difference in cytokines between controls and allografts.

I have already alluded to the second question. I think that the immunologic parameters to observe are the $T$ cells, which we can look at and detect in a shortened MLC. If anything destroys the valves, it will be $\mathrm{T}$ cells. Perhaps those three individuals with the high $\mathrm{T}$-cell reactivities out of proportion to the others may be the ones that we have to watch.

I agree entirely with you regarding immune suppression. We could use a drug such as cyclosporine for the first 2 to 3 months after implantation, stop the drug, and then see an immune response. Alternatively, immune suppression for the first several months may protect the valve until alterations such as loss of endothelium make the valve an immunologically privileged site. The valve would be less prone to attack at that stage, and remaining viable fibroblasts would be protected.

Dr. David B. Ross (Halifax, Nova Scotia, Canada). We found in a small series of children with homografts in the right ventricular outflow tract that very short preservation times similar to those you reported were associated with increased failure. Have you looked at whether children have a qualitatively or a quantitatively different response than this group of adults that you have presented?

Do you have any information about which of these adults, if any, received blood transfusions? Is it possible that children do more poorly because a higher percentage of them would have received multiple transfusions at this operation or during previous ones?

Dr. Hogan. No, we haven't looked at children, and that study needs to be done. I would be surprised if the results were qualitatively different from what we have shown. There are a few things that I omitted from the data, and one was that there was no relation between results and parameters such as blood transfusions and whether the patients got a large amount of tissue in an aortic root or just got a subcoronary valve. There was no relation to blood transfusions.

Dr. Alain F. Carpentier (Paris, France). Have you analyzed separately the aortic remnants and the valve cusp for anti-T and anti-B antibodies, and if so, was there any difference? If there is a difference, knowing that calcification is more common in the aortic remnant, do you see any correlation between calcification and immunologic reaction, and have you analyzed the calcium content on these two parts? Was there any correlation between valve failure and recipient $T$-cell reactivity?

Dr. Hogan. The studies that I described were done in the last 24 months, and we do not have any clinical correlates for the cohort of 20 patients. I cannot tell you whether there is a correlation between these immunologic findings and calcification or valve failure. In an abstract presented at another meeting earlier this year, donorreactive recipient $T$ cells were cultured from explanted valves. Whether the $\mathrm{T}$ cells were damaging the valve is unknown.

\section{Bound volumes available to subscribers}

Bound volumes of The Journal of Thoracic and Cardiovascular Surgery are available to subscribers (only) for the 1996 issues from the Publisher, at a cost of $\$ 100.50$ for domestic, $\$ 128.94$ for Canadian, and $\$ 120.50$ for international subscribers for Vol. 111 (January-June) and Vol. 112 (July-December). Shipping charges are included. Each bound volume contains a subject and author index and all advertising is removed. Copies are shipped within 60 days after publication of the last issue of the volume. The binding is durable buckram with the Journal name, volume number, and year stamped in gold on the spine. Payment must accompany all orders. Contact Mosby-Year Book, Inc., Subscription Services, 11830 Westline Industrial Drive, St. Louis, Missouri 63146-3318, USA; phone $800-453-4351$ or 314-453-4351.

Subscriptions must be in force to qualify. Bound volumes are not available in place of a regular Journal subscription. 